\title{
Agitated behaviors among elderly people with dementia living in their home in Taiwan
}

This article was published in the following Dove Press journal:

Clinical Interventions in Aging

\author{
Huei-Ling Huang ${ }^{1,2}$ \\ Yea-Ing L Shyu ${ }^{1,3-5}$ \\ Wen-Chuin $\mathrm{Hsu}^{6}$ \\ 'Department of Gerontological \\ Care and Management, Chang \\ Gung University of Science and \\ Technology, Taoyuan, Taiwan; ${ }^{2}$ Nursing \\ Department, Taoyuan Chang Gung \\ Memorial Hospital, Taoyuan, Taiwan; \\ ${ }^{3}$ School of Nursing, College of \\ Medicine \& Healthy Aging Research \\ Center, Chang Gung University, \\ Taoyuan, Taiwan; ${ }^{4}$ Department of \\ Orthopedic Surgery, Linkou Chang \\ Gung Memorial Hospital, Taoyuan, \\ Taiwan; ${ }^{5}$ Department of Nursing, \\ Kaohsiung Chang Gung Memorial \\ Hospital, Kaohsiung, Taiwan; ${ }^{6}$ Chang \\ Gung Dementia Center, Department \\ of Neurology, Chang Gung University \\ and Memorial Hospital, Taoyuan, \\ Taiwan
}

\begin{abstract}
Background/aims: Limited research has been conducted on agitated behavior in Taiwan and dementia among community-dwelling elderly. Therefore, this study focused on community elderly with dementia and a factor analysis of an inventory of their agitated behaviors was conducted.
\end{abstract}

Patients and methods: Participants $(\mathrm{N}=221)$ completed the Chinese Cohen-Mansfield Agitation Inventory, community form. Item analysis and exploratory factor analysis assessed reliability, validity, and the underlying factor structure.

Results: Five factors were extracted and accounted for $44.53 \%$ of the total variance. This study classified agitated behaviors into 5 main subtypes: physically agitated behaviors, destructive behaviors, verbally agitated behaviors, handling things behavior, and aggressive behaviors.

Conclusion: The results indicate that differences in the agitated behavior of elderly with dementia exist with respect to cultural background and setting. This novel research and its findings serve as a reference for assessing the agitated behaviors of elderly with dementia living in their homes. Applications may exist for other countries with Chinese/Taiwanese populations.

Keywords: agitation, aggressive behavior, behavioral problem, caregiver, factor analysis, dementia

\section{Introduction}

The prevalence distribution of agitated behavior among elderly with dementia living in communities has risen from $22 \%$ to $88 \% .{ }^{1-3}$ Due to differences in the definition of agitated behavior and in the evaluation instruments used among various studies, a rather significant differentiation exists in this prevalence range. Agitated behavior is the main source of distress for caregivers of elderly with dementia; therefore, provision of a valid and reliable evaluation instrument can help caregivers to assess the agitated behavior, understand the stage of progression, and evaluate the results of treatment intervention. ${ }^{4,5}$ The agitation inventory that was developed by Cohen-Mansfield ${ }^{6}$ with creditability is commonly used for the assessment of agitated behavior in elderly people with dementia.

Previous studies have indicated that various classified behavioral problems may stem from a common cause, and a universal treatment can be applied according to the subtype of each behavioral problem. ${ }^{7-10}$ Verbally aggressive behavior (VAB), such as complaining, screaming, and repetitive sentences or questions, may stem from a need for assistance with physiological or emotional discomfort. Physically nonaggressive behavior (PNAB), such as pacing, is found to be linked to healthier individuals. Thus, it can be inferred that PNAB may possibly be beneficial to elderly with severe dementia. It is therefore recommended that caregivers permit or even promote such behaviors. Physically aggressive behavior (PAGB) may be caused by nerve damage from severe
Correspondence: Yea-Ing L Shyu School of Nursing, Chang Gung University, 259 Wen-Hwa Ist Road, Kwei-Shan, Taoyuan 333, Taiwan Tel +88632118800 ext 5275 Fax +88632118400 Email yeaing@mail.cgu.edu.tw 
dementia, the feeling of abandonment, or prolonged negative personal relationships. ${ }^{7}$ These abovementioned results illustrate that in order to understand agitation in elderly with dementia, not only do their individual behaviors need to be monitored, but investigations specifically focusing on different types of agitated behavior must also be conducted.

A small number of studies have investigated the classification of agitated behavior. The most common subtypes include 1) PNAB, such as restlessness and pacing; 2) PAGB, such as hitting, grabbing onto people, pushing, and kicking; 3) verbally nonaggressive behavior (VNAB), such as complaining and constant requests for attention; and 4) verbally aggressive behavior (VAGB), such as cursing, verbal aggression, and temper outbursts. ${ }^{11-14}$

The Cohen-Mansfield ${ }^{11,13}$ Agitation Inventory, community form (CMAI-C), was used in the assessment of agitated behavior of elderly in day care centers, and 3 types of agitated behaviors were extracted from the factor analysis: VNAB, PNAB, and VAGB. During this study, though the criteria for factor extraction for PAGB was not reached because of the impact it has on the patient's family, Cohen-Mansfield still divided the community agitated behavior scale into four subtypes. First, "physically nonaggressive behavior," which includes restlessness, pacing, or wandering, trying to get to a different place, inappropriate dressing or undressing, repetitious mannerisms, and handling things inappropriately. Second, "physically aggressive behavior," which includes hitting people, themselves, or objects, kicking people or objects, grabbing onto or clinging to people, pushing other people, biting people or objects, and scratching people, themselves, or objects. Third, "verbally nonaggressive behavior," which includes repetitive sentences or questions, relevant (or irrelevant) verbal interruptions, complaining or whining, constant requests for attention, negativism, uncooperativeness, or unwillingness, and being verbally bossy or pushy. Fourth, "verbally aggressive behavior," which includes making strange noises, screaming/shouting or howling, cursing or verbally threatening behavior, and temper outbursts. ${ }^{11,13}$

The abovementioned 3 or 4 subtypes of classification of agitated behavior are currently the most common classification methods. However, as there are differences in agitated behavior between institutionalized elderly with dementia and elderly with dementia staying at home, and their cultural backgrounds, researchers from different countries continue to investigate different methods of classification. ${ }^{12,14,15}$ In Taiwan, limited studies have been conducted on the agitated behavior of institutionalized dementia patients. In regard to the assessment of agitated behaviors, only Lin et $\mathrm{al}^{15}$ has tested the reliability and validity of the Chinese CohenMansfield Agitation Inventory, community form (CCMAI-C) with institutionalized dementia patients, but its subtype has yet to be investigated, likewise for the studies pertaining to the agitated behavior assessment of community elderly with dementia and the investigation on the assessment's subtype. Therefore, this study will focus on elderly with dementia living in their own homes and conduct a factor analysis of their agitated behaviors.

\section{Patients and methods}

\section{Study setting and participants}

Participants were recruited from neurological clinics within 3 hospitals and a community care management center in northern Taiwan. Patients were included in the study if they met the following criteria: 1) diagnosed with dementia by a psychiatrist or neurologist, 2) $>65$ years old, 3) living in a home setting in northern Taiwan, and 4) scored $>50$ on the CCMAI-C. Inclusion criteria for caregivers were 1) living with a dementia patient, 2) spending the majority of time on the patient's care, and 3) 18 years or older. Participants were assessed for study outcomes in their homes.

\section{Design and procedure}

A cross-sectional, exploratory design was used to investigate the behavioral problems of elderly individuals with dementia. This research was approved by the Human Subjects Protection Committee of Chang Gung Memorial Hospital in Taiwan.

A research nurse contacted eligible subjects at the outpatient clinics of 3 hospitals and cases referred by the local care management center to explain the purpose and method of the study, subjects' right to withdraw participation at any time, and to obtain written consent. All participants provided written informed consent. Data were collected by caregivers' self-report regarding to care receivers' behavioral problems.

\section{Measurement of agitation}

Agitation was measured by the CCMAI-C;6,16-18 the CCMAI-C has been shown to be valid and reliable for a Taiwanese sample. ${ }^{19}$ There are 37 items in the English version of CMAI for Community and 44 items in the Chinese version. The additional 7 items in the CCMAI-C are "Unable to sleep," "Complaining of being hurt or stolen by someone," "Claiming to kill him/herself," "Picking things up incessantly," "Searching for things incessantly," "Requesting 
food incessantly," and "Going to the toilet incessantly."18 From the results of original factor analysis of CCMAI, that the additional 7 items were not classified into subtypes of the original CCMAI. However, all the items were still included in the measurement of overall agitation according to the original author's suggestion.

Family caregivers were asked to report the frequency of the agitation in the preceding 2 weeks; each item is rated on a 7-point scale, ranging from 1 (never happened) to 7 (several times in an hour). In our previous study, Cronbach's alpha $(\alpha)$ for the overall scale was 0.88 . Cronbach's $\alpha$ for the PNAB, PAGB, VAGB, and VNAB subscales were 0.79, 0.75, 0.87, and 0.78 , respectively. ${ }^{19}$

\section{Data analysis}

Data were analyzed using SPSS version 20.0 (IBM Corporation, Armonk, NY, USA) and AMOS version 20.0 (IBM Corporation). First, the interitem consistency and discriminability for each item of the CCMAI-C was carried out by item analysis according to the critical ratio (CR) and itemtotal correlation (ITC) value. Second, the construct validity of the CCMAI-C was performed using exploratory factor analysis with principal axis factoring and direct oblimin rotation. Third, the internal consistencies of the CCMAI-C overall scale and subscales were estimated by Cronbach's $\alpha$.

\section{Results}

\section{Participant characteristics}

Of the 630 dementia patients screened, 251 patients and their caregivers met the inclusion criteria, and 221 agreed to participate in the study. The majority were female (56\%) with an average age of 78.4 years $(\mathrm{SD}=6.74)$. Furthermore, $47 \%$ had no formal education and $42 \%$ were mildly dependent on caregivers to perform activities of daily living (ADLs), as indicated by an average Chinese Barthel Index score of 77.70 ( $\mathrm{SD}=27.15)$. All patients had an average Mini-Mental State Examination score of 12 (SD =7). As regards dementia severity, $48 \%$ had mild dementia, $33 \%$ had moderate dementia, and $19 \%$ had severe dementia as determined by the Clinical Dementia Rating Scale. The majority were diagnosed with Alzheimer's disease (55\%), $38 \%$ with vascular dementia, and on average participants had dementia for 38 months $(\mathrm{SD}=28)$. The patients' characteristics are listed in Table 1.

\section{Item analysis}

Item analysis was performed using the CR test and ITC. The intention was to determine the CR value in order to assess
Table I Patient characteristics $(\mathrm{N}=22 \mathrm{I})$

\begin{tabular}{|c|c|c|}
\hline Characteristics & Mean \pm SD/range & n (\%) \\
\hline Age (years) & $78.4 \pm 6.74$ & \\
\hline \multicolumn{3}{|l|}{ Gender } \\
\hline Male & & $97(43.9)$ \\
\hline Female & & $124(56.1)$ \\
\hline \multicolumn{3}{|l|}{ Education background } \\
\hline No formal education & & $103(46.6)$ \\
\hline Primary school & & $56(25.3)$ \\
\hline Junior high school & & $27(12.2)$ \\
\hline High school & & $19(8.6)$ \\
\hline College or above & & $16(7.3)$ \\
\hline ADL performance & $77.70 \pm 27.15$ & \\
\hline 0-20 (severely dependent) & & $14(6.3)$ \\
\hline 2I-60 (moderately dependent) & & $4 \mid(18.6)$ \\
\hline 6I-95 (mildly dependent) & & $93(42.1)$ \\
\hline 96-100 (independent) & & $73(33.0)$ \\
\hline Cognitive status & $12.40 \pm 6.85$ & \\
\hline \multicolumn{3}{|l|}{ Clinical dementia rating } \\
\hline Mild & & $107(48.4)$ \\
\hline Moderate & & $72(32.6)$ \\
\hline Severe & & $42(19.0)$ \\
\hline Duration of illness (months) & $37.80 \pm 28.17$ & \\
\hline Range & $2-92$ & \\
\hline \multicolumn{3}{|l|}{ Diagnosis } \\
\hline Alzheimer's disease & & $122(55.2)$ \\
\hline Vascular dementia & & $83(37.6)$ \\
\hline Mixed dementia & & $16(7.2)$ \\
\hline
\end{tabular}

Abbreviation: $A D L$, activity of daily living.

internal consistency as measured through item correlation with the total score. Interitem correlation will also examine the similarity among test items. ITC obtained the correlation coefficient ranging from 0.3 to 0.8 . Significant items with a $\mathrm{CR}$ value of 0.01 were extracted with a CR test. Items that failed to reach the standard of both the ITC and CR were excluded. As a result, 5 items from the CCMAI-C were deleted including verbal sexual advances, physical sexual advances, grabs onto or clings to people, pushes other people, and hurts self with harmful object, with 37 items remaining. A summary of the item analysis is given in Table 2 .

\section{Factor analysis}

Factor extraction was based on the following criteria: 1) eigenvalues $>1,2$ ) factor loadings $\geq 0.3$, and 3) 3 or more items loading on any given factor. Of the remaining 37 items 5 factors were extracted, which accounted for $44.53 \%$ of the total variance. Each factor accounted for $21.90 \%, 7.14 \%$, $5.68 \%, 5.25 \%$, and $4.56 \%$ of the variance, respectively.

The first factor, labeled physically agitated behavior (PAB), contained 10 items. The second factor was labeled destructive behavior (DB) and contained 4 items. The third 
Table 2 Item analysis of the CCMAI-C (items $=42$ )

\begin{tabular}{|c|c|c|c|c|c|c|}
\hline \multirow[t]{2}{*}{ Item } & \multirow[t]{2}{*}{ Mean } & \multirow[t]{2}{*}{ SD } & \multirow{2}{*}{$\begin{array}{l}\text { Critical } \\
\text { ratio }\end{array}$} & \multicolumn{3}{|c|}{ Test for homogeneity } \\
\hline & & & & $\begin{array}{l}\text { Item-total } \\
\text { correlation }\end{array}$ & $\begin{array}{l}\text { Corrected item- } \\
\text { total correlation }\end{array}$ & $\begin{array}{l}\text { Cronbach's } \alpha \\
\text { if item deleted }\end{array}$ \\
\hline I. Repetitive sentences or questions & 4.43 & 2.18 & $-6.04 *$ & $0.37 * *$ & 0.29 & 0.88 \\
\hline 2. Relevant verbal interruptions & 2.02 & 1.72 & $-2.97 * *$ & $0.25 * *$ & 0.17 & 0.88 \\
\hline 3. Irrelevant verbal interruptions & 2.15 & 1.87 & $-6.3 I^{*}$ & $0.50 * *$ & 0.44 & 0.87 \\
\hline 4. Making strange noises & 1.70 & 1.52 & $-6.09 *$ & $0.44 * *$ & 0.38 & 0.88 \\
\hline 5. Screaming/shouting or howling & 1.48 & 1.25 & $-3.87^{*}$ & $0.32 * *$ & 0.27 & 0.88 \\
\hline 6. Complaining or whining & 2.33 & 1.73 & $-6.35^{*}$ & $0.52 * *$ & 0.47 & 0.87 \\
\hline 7. Unwarranted requests for attention or help & 1.88 & 1.57 & $-7.89 *$ & $0.56 * *$ & 0.51 & 0.87 \\
\hline 8. Negativism, uncooperativeness, unwillingness & 2.55 & 1.73 & $-6.45^{*}$ & $0.44 * *$ & 0.38 & 0.88 \\
\hline 9. Cursing or verbally threatening behavior & 1.81 & 1.39 & $-6.48^{*}$ & $0.54^{* *}$ & 0.50 & 0.87 \\
\hline 10. Spitting & 1.68 & 1.60 & $-5.02^{*}$ & $0.36 * *$ & 0.30 & 0.88 \\
\hline II. Verbally bossy or pushy & 1.57 & 1.33 & $-5.27^{*}$ & $0.49 * *$ & 0.45 & 0.88 \\
\hline 12. Making verbal sexual advances & 1.10 & 0.49 & -1.73 & $0.14^{* * *}$ & 0.12 & 0.88 \\
\hline 13. Making physical sexual advances/exposure & I.II & 0.49 & -1.92 & $0.28 * *$ & 0.26 & 0.88 \\
\hline 14. Restlessness or fidgeting behavior & 2.90 & 2.25 & $-11.29 *$ & $0.62 * *$ & 0.56 & 0.87 \\
\hline 15. Pacing or aimless wandering & 2.57 & 2.13 & $-7.08^{*}$ & $0.51 * *$ & 0.45 & 0.88 \\
\hline 16. Trying to get to a different places & 1.75 & 1.38 & $-4.62^{*}$ & $0.37 * *$ & 0.32 & 0.88 \\
\hline 17. Inappropriate dressing or disrobing & 1.67 & 1.31 & $-6.18^{*}$ & $0.4 I^{* *}$ & 0.36 & 0.88 \\
\hline 18. Repetitious mannerisms & 2.31 & 2.11 & $7.36 *$ & $0.56 * *$ & 0.50 & 0.87 \\
\hline 19. Handling things inappropriately & 2.05 & 1.78 & $-7.96 *$ & $0.59 * *$ & 0.54 & 0.87 \\
\hline 20. Grabbing or snatching things from others & 1.11 & 0.57 & $-2.55 * * *$ & $0.37^{* *}$ & 0.35 & 0.88 \\
\hline 21. Hoarding or collecting objects & 2.13 & 1.78 & $-7.27^{*}$ & $0.53 * *$ & 0.47 & 0.87 \\
\hline 22. Hiding things & 2.08 & 1.75 & $-7.88^{*}$ & $0.47^{* *}$ & 0.41 & 0.88 \\
\hline 23. Temper outburst/anger & 3.04 & 1.75 & $8.67^{*}$ & $0.57^{* *}$ & 0.52 & 0.87 \\
\hline 24. Hitting people, self, or objects & 1.35 & 0.86 & $-3.76^{*}$ & $0.53 * *$ & 0.51 & 0.88 \\
\hline 25. Kicking people or objects & 1.09 & 0.44 & $-3.02 * *$ & $0.48 * *$ & 0.47 & 0.88 \\
\hline 26. Throwing things & 1.30 & 0.97 & $-4.31 *$ & $0.46 * *$ & 0.42 & 0.88 \\
\hline 27. Tearing or destroying objects & 1.20 & 0.87 & $-3.22 * *$ & $0.43^{* *}$ & 0.40 & 0.88 \\
\hline 28. Grabbing onto or clinging to people & 1.22 & 0.87 & $-2.12^{* * *}$ & $0.29 * *$ & 0.26 & 0.88 \\
\hline 29. Pushing other people & 1.20 & 0.74 & -1.93 & $0.29 * *$ & 0.26 & 0.88 \\
\hline 30. Biting people or things & 1.05 & 0.40 & $-2.03 * * *$ & $0.4 I^{* *}$ & 0.40 & 0.88 \\
\hline 31. Scratching people, self, or things & 1.12 & 0.61 & $-2.95 * *$ & $0.28 * *$ & 0.26 & 0.88 \\
\hline 32. Hurting self with harmful object & 1.06 & 0.49 & -1.93 & $0.29 * *$ & 0.28 & 0.88 \\
\hline 33. Hurting others with harmful objects & 1.06 & 0.38 & $-2.54 * * *$ & $0.47 * *$ & 0.46 & 0.88 \\
\hline 34. Appear to fall intentionally & 1.06 & 0.33 & $-2.68 * *$ & $0.35 * *$ & 0.33 & 0.88 \\
\hline 35. Eating/drinking nonfood substances & 1.09 & 0.43 & $-3.23 * *$ & $0.46 * *$ & 0.45 & 0.88 \\
\hline 36. Unable to sleep & 2.80 & 1.76 & $-5.70 *$ & $0.39 * *$ & 0.32 & 0.88 \\
\hline 37. Complaining of being hurt or stolen & 1.91 & 1.54 & $-7.39 *$ & $0.51 * *$ & 0.46 & 0.87 \\
\hline 38. Claiming to kill him/herself & 1.24 & 0.81 & $-4.07^{*}$ & $0.40 * *$ & 0.37 & 0.88 \\
\hline 39. Picking things up incessantly & 1.63 & $\mathrm{I} .47$ & $-5.66 *$ & $0.40 * *$ & 0.35 & 0.88 \\
\hline 40. Searching for things incessantly & 2.46 & 1.94 & $-9.42 *$ & $0.55^{* *}$ & 0.49 & 0.87 \\
\hline 4I. Requesting food incessantly & 2.33 & 1.93 & $-5.52^{*}$ & $0.37 * *$ & 0.30 & 0.88 \\
\hline 42. Going to the toilet incessantly & 2.24 & 2.16 & $-4.46^{*}$ & $0.38^{* *}$ & 0.30 & 0.88 \\
\hline
\end{tabular}

Note: $* p<0.05$, **p $<0.01$, *** $p<0.00$ I.

Abbreviation: CCMAI-C, Chinese Cohen-Mansfield Agitation Inventory, community form.

factor, labeled VAB, contained 9 items. The fourth factor was labeled handling things behavior (HTB) and contained 5 items while the fifth factor, labeled AGB, contained nine items. Details of the factor structure and item loadings are presented in Table 3.

\section{Reliability}

The internal consistency for the overall scale was 0.88 . For each subtype of agitation, internal consistency was as follows: PAB, $\alpha=0.75$; $\mathrm{DB}, \alpha=0.69$; VAB, $\alpha=0.75$; HTB, $\alpha=0.76$; and AGB, $\alpha=0.71$. All values indicated 
Table 3 Factor structure and reliability of the CCMAI-C (items $=37$ )

\begin{tabular}{|c|c|c|c|c|c|}
\hline Item & Factor I PAB & Factor 2 DB & Factor 3 VAB & Factor 4 НТВ & Factor 5 AGB \\
\hline 14. Restlessness or fidgety behavior & 0.677 & & & & \\
\hline 15. Pacing/aimless wandering & 0.659 & & & & \\
\hline 18. Repetitious mannerisms & 0.516 & & & & \\
\hline 8. Negativism, uncooperativeness, or unwillingness & 0.499 & & & & \\
\hline 23. Temper outburst/anger & 0.488 & & & & \\
\hline 16. Trying to get to a different places & 0.465 & & & & \\
\hline 36. Unable to sleep & 0.402 & & & & \\
\hline 10. Spitting & 0.369 & & & & \\
\hline 17. Inappropriate dressing or disrobing & 0.360 & & & & \\
\hline 42. Going to the toilet incessantly & 0.303 & & & & \\
\hline 30. Biting people or things & & -0.940 & & & \\
\hline 33. Hurting others with harmful objects & & -0.836 & & & \\
\hline 27. Tearing/destroying objects & & -0.504 & & & \\
\hline 26. Throwing things & & -0.476 & & & \\
\hline 3. Unrelated verbal interruptions & & & 0.629 & & \\
\hline 7. Making unwarranted requests for attention & & & 0.609 & & \\
\hline 6. Complaining or whining & & & 0.523 & & \\
\hline 9. Cursing or verbally threatening behavior & & & 0.508 & & \\
\hline II. Being verbally bossy or pushy & & & 0.488 & & \\
\hline I. Repetitive sentences or questions & & & 0.487 & & \\
\hline 2. Relevant verbal interruptions & & & 0.462 & & \\
\hline 4I. Requesting food incessantly & & & 0.410 & & \\
\hline 37. Accused of being hurt or stolen & & & 0.398 & & \\
\hline 22. Hiding things & & & & -0.685 & \\
\hline 19. Handling things inappropriately & & & & -0.588 & \\
\hline 21. Hoarding or collecting objects & & & & -0.587 & \\
\hline 40. Searching for things incessantly & & & & -0.583 & \\
\hline 39. Picking things up incessantly & & & & -0.557 & \\
\hline 25. Kicking people or objects & & & & & -0.762 \\
\hline 20. Grabbing or snatching things from others & & & & & -0.662 \\
\hline 24. Hitting people/self/objects & & & & & -0.559 \\
\hline 38. Claiming to kill him/herself & & & & & -0.539 \\
\hline 34. Appearing to fall intentionally & & & & & -0.523 \\
\hline 31. Scratching people/self/things & & & & & -0.501 \\
\hline 35. Eating/drinking nonfood substances & & & & & -0.474 \\
\hline 4. Making strange noises & & & & & -0.461 \\
\hline 5. Screaming/shouting or howling & & & & & -0.405 \\
\hline Eigenvalues & 8.10 & 2.64 & 2.10 & 1.94 & 1.69 \\
\hline Explain variance (\%) & 21.90 & 7.14 & 5.68 & 5.25 & 4.56 \\
\hline Cumulative variance (\%) & 21.90 & 29.04 & 34.73 & 39.97 & 44.53 \\
\hline Cronbach's $\alpha$ & 0.75 & 0.69 & 0.75 & 0.76 & 0.71 \\
\hline
\end{tabular}

Abbreviations: AGB, aggressive behavior; CCMAI-C, Chinese Cohen-Mansfield Agitation Inventory, community form; DB, destructive behavior; HTB, handling things behavior; PAB, physically agitated behavior; $\mathrm{VAB}$, verbally agitated behavior.

acceptable reliability. Results of the reliability analysis are shown in Table 3.

\section{Discussion}

Through exploratory factor analysis, this study has classified agitated behaviors into 5 subtypes: $\mathrm{PAB}, \mathrm{DB}, \mathrm{VAB}$, HTB, and AGB. These differ from the 4 subtypes of agitated behavior derived by Cohen-Mansfield. ${ }^{13}$
In this study, negative/uncooperative behaviors appeared in the subtype PAB, while in the CMAI-C, it appears within VNAB. This may have been caused by the refusal to cooperate with or reluctance to participate in the activities of this study. Activities such as eating, bathing, or going out involve a physical elements and are therefore classified as PAB. Regardless of this study or the findings of the CMAI-C, negative/uncooperative behaviors are all classified under nonaggressive behaviors. 
There is only 1 verbal subtype, $\mathrm{VAB}$, in the factor structure identified in this study, and it is similar to the results of Cohen-Mansfield's investigation of agitated behavior for elderly in day care centers. The results of Cohen-Mansfield et al's ${ }^{11}$ study identified 3 types of agitated behaviors: 1) PNAB, 2) VAB, and 3) AGB. Items "making strange noises" and "screaming/shouting or howling" appear in AGB in this study, while they appear in VAGB in CMAI-C. Irrespective of this, the abovementioned behaviors are both classified under aggressive behaviors.

A notable finding from the current research is that the second factor and the fourth factor, which are "DB" and "HTB", respectively, are not included in Cohen-Mansfield's CMAI-C. While in the Dutch and Korean version of their studies as well as the study by Rabinowitz et $\mathrm{al}^{20}$ a subtype similar to HTB was found. Labeled as "hiding/hoarding," this factor consisted entirely of hiding and hoarding behaviors. In this study, the HTB subtype contained 5 varying items (handling things inappropriately, hoards or collects objects, hiding things, picking things up incessantly, and searching for things incessantly). Such a difference may arise from the sample of the current research, elderly with dementia living at home, as other studies assessed those residing in nursing homes. The difference in setting may produce differences in the agitated behaviors exhibited. Furthermore, this subtype is not represented in other researches, an outcome that may be influenced by limiting the number factors extracted to 3 or the low rate of occurrences. ${ }^{5,20}$

Both subtypes DB and HTB are classified under "things" related to agitated behavior. During the process of gathering data, the interviews with family caregivers conducted in the current research reveal that elderly with dementia living in their homes demonstrate the behavior of collecting, hoarding, and/or destroying items. Examples of such behavior include hoarding or destroying tissues, papers, slippers, foods, and other items. This phenomenon is especially apparent in female patients with dementia. As elderly in Taiwan tend to exhibit the characteristics of saving and collecting, the question of whether this phenomenon is related to the life of the elderly and/or the difference in cultures in the East and West needs further investigation.

The results of this study also identified that being "unable to sleep" and "going to the toilet incessantly" are 2 common behaviors of the elderly with dementia who live in their homes in Taiwan. However, the community form of Cohen-Mansfield's CMAI does not contain these 2 behaviors; furthermore, the result classification also differs from country to country. With the consideration of differences between cultures, it is recommended that local measuring scales or classification methods be used in the future when monitoring of agitated behavior in elderly with dementia is needed.

The results indicate that differences in the agitated behavior of elderly with dementia exist with respect to cultural background and setting. Additionally, participants were mostly elderly with mild or moderate dementia (81\%), and those with severe dementia formed the minority (19\%). As a result, occurrences of the AGB in severe dementia in this study were rare. In Taiwan, as severe dementia patients increase the difficulty of care for family caregivers, most of these patients have been institutionalized, thereby making the majority of community cases mild and moderate ${ }^{19,21}$ and resulting a limitation to this study, as it is difficult to detect the behavior characteristics of severe dementia patients. However, this study does show the characteristics of care for dementia patients living at home in Taiwan.

\section{Conclusion}

To our knowledge, the vast majority of current research on the classification of agitation focuses on patients living in nursing homes and rarely specifies patients cared for by family caregivers. Therefore, these results not only can serve as a source of reference for the assessment of agitated behaviors in elderly with dementia living at home in Taiwan but also may be applicable to other countries with Chinese populations and those where health care providers support Chinese/Taiwanese immigrants. Future studies exploring how patients should be treated differently according to the subtype of agitated behavior and/or specific interventions for different subtypes of behavioral problems are suggested.

\section{Acknowledgments}

This research was supported by the National Science Council, Taiwan (NSC 99-2314-B-255-009-MY2), and Healthy Aging Research Center, Chang Gung University (EMRPD1H0361, EMRPD1H0551). We would like to thank the nurses and doctors working in the neurological clinics of Chang Gung Memorial Hospital for their participation in this study. We would also like to express our special thanks to the people with dementia and their family caregivers who participated in this study.

The abstract of this paper was presented at the Alzheimer's Association International Conference 2014 under the name "Agitated behaviors among elderly people with dementia living in their home in Taiwan" as a poster presentation with interim findings. The poster's abstract was published in "Poster Abstracts" in Alzheimer's \& Dementia, Volume 10, Issue 4, Supplement: http://www.alzheimersanddementia. com/article/S1552-5260(14)01588-X/abstract. 


\section{Author contributions}

All authors contributed toward data analysis, drafting and revising the paper and agree to be accountable for all aspects of the work.

\section{Disclosure}

The authors report no conflicts of interest in this work.

\section{References}

1. Haupt M, Kurz A, Jänner M. A 2-year follow-up of behavioral and psychological symptoms in Alzheimer. Dement Geriatr Cogn Disord. 2000;11(3):147-152.

2. Lyketsos CG, Steinberg M, Tschanz JT, Norton MC, Steffens DC, Breitner JC. Mental and behavioral disturbances in dementia: findings from the Cache County Study on memory in aging. Am J Psychiatry. 2000;157(5):708-714.

3. Tampi RR, Williamson D, Muralee S, et al. Behavioral and psychological symptoms of dementia: part I - epidemiology, neurobiology, heritability, and evaluation. Clin Geriatr. 2011;19:41-46.

4. Travis Seidl JN, Massman PJ. Cognitive and functional correlates of NPI-Q scores and symptom clusters in mildly demented Alzheimer patients. Alzheimer Dis Assoc Disord. 2016;30(2):145-151.

5. Choi SSW, Budhathoki C, Gitlin LN. Co-occurrence and predictors of three commonly occurring behavioral symptoms in dementia: agitation, aggression, and rejection of care. Am J Geriatr Psychiatry. 2017;25(5): 459-468.

6. Cohen-Mansfield J. Instruction Manual for the Cohen-Mansfield Agitation Inventory (CMAI). Rockville, MD: The Research Institute of the Hebrew Home of Greater Washington; 1991.

7. Cohen-Mansfield J, Marx MS, Werner P. Agitation in elderly persons: an integrative report of findings in a nursing home. Int Psychogeriatr. 1992;4(Suppl 2):221-240.

8. Street JS, Clark WS, Gannon KS, et al. Olanzapine treatment of psychotic and behavioral symptoms in patients with Alzheimer disease in nursing care facilities: a double-blind, randomized, placebo-controlled trial. Arch Gen Psychiatry. 2000;57(10):968-976.

9. Lawlor B, Bhriain SN. Psychosis and behavioral symptoms of dementia: defining the role of neuroleptic interventions. Int J Geriatr Psychiatry. 2001;16(Supp1 1):S2-S6.
10. van der Linde RM, Denning T, Matthews FE, Brayne C. Grouping of behavioural and psychological symptoms of dementia. Int $J$ Geriatr Psychiatry. 2014;29(6):562-568.

11. Cohen-Mansfield J, Werner P, Watson V, Pasis S. Agitation among elderly persons at adult day-care centers: the experiences of relatives and staff members. Int Psychogeriatr. 1995;7(3):447-458.

12. Choy CN, Lam LC, Chan WC, Li SW, Chiu HF. Agitation in Chinese elderly: validation of the Chinese of the Cohen-Mansfield agitation inventory. Int Psychogeriatr. 2001;13(3):325-335.

13. Cohen-Mansfield J. Agitation in the elderly: a definitional and theoretical conceptualizations. In: Hay DP, Kennedy JS, Grossberg GT, Klein DT, Hay LK, editors. Agitation in Patients with Dementia: A Practical Guide to Diagnosis and Management. Washington, DC: American Psychiatric Publishing; 2003:1-22.

14. Zuidema SU, de Jonghe JF, Verhey FR, Koopmans RT. Agitation in Dutch institutionalized patients with dementia: factor analysis of the Dutch version of the Cohen-Mansfield agitation inventory. Dement Geriatr Cogn Disord. 2007;23(1):35-41.

15. Lin LC, Kao CC, Tzeng YL, Lin YJ. Equivalence of Chinese version of the Cohen-Mansfield agitation inventory. J Adv Nurs. 2007;59(2): 178-185.

16. Cohen-Mansfield J, Marx MS, Rosenthal AS. A description of agitation in a nursing home. J Gerontol. 1989;44(3):M77-M84.

17. Lai CKY. The use of the Cohen-Mansfield agitation inventory in the assessment of agitation in people with dementia: applicability in Hong Kong. Hong Kong J Gerontol. 2002;14:66-69.

18. Lai CKY. The Cohen-Mansfield agitation inventory: development of a Chinese version. Chin J Nurs. 2010;45:500-504.

19. Huang HL, Shyu YI, Chen ST, Hsu WC. Caregiver self-efficacy for managing behavioral problems of older people with dementia in Taiwan correlates with care receivers' behavioral problems. J Clin Nurs. 2009; 18(18):2588-2595.

20. Rabinowitz J, Davidson M, DeDeyn PP, Katz I, Brodaty H, CohenMansfield J. Factor analysis of the Cohen-Mansfield agitation inventory in three large samples of nursing home patients with dementia and behavioral disturbance. Am J Geriatr Psychiatry. 2005;13(11):991-998.

21. Huang HL, Shyu YI, Chen MC, Chen ST, Lin LC. A pilot study on a home-based caregiver training program for improving caregiver selfefficacy and decreasing the behavioral problems of elders with dementia in Taiwan. Int J Geriatr Psychiatry. 2003;18(4):337-345.
Clinical Interventions in Aging

\section{Publish your work in this journal}

Clinical Interventions in Aging is an international, peer-reviewed journal focusing on evidence-based reports on the value or lack thereof of treatments intended to prevent or delay the onset of maladaptive correlates of aging in human beings. This journal is indexed on PubMed Central, MedLine,

\section{Dovepress}

CAS, Scopus and the Elsevier Bibliographic databases. The manuscript management system is completely online and includes a very quick and fair peer-review system, which is all easy to use. Visit http://www.dovepress. com/testimonials.php to read real quotes from published authors. 